\title{
La Valeur de l'Art. Exposition, marché, critique et public au XVIII siècle, sous la direction de Jesper
}

\section{Rasmussen}

\section{Bianca Gai}

\section{(2) OpenEdition}

\section{Journals}

\section{Edizione digitale}

URL: http://journals.openedition.org/studifrancesi/5949

DOI: 10.4000/studifrancesi.5949

ISSN: 2421-5856

\section{Editore}

Rosenberg \& Sellier

\section{Edizione cartacea}

Data di pubblicazione: 1 mai 2011

Paginazione: 169-170

ISSN: 0039-2944

\section{Notizia bibliografica digitale}

Bianca Gai, «La Valeur de l'Art. Exposition, marché, critique et public au xvIII' siècle, sous la direction de Jesper Rasmussen», Studi Francesi [Online], 163 (LV | I) | 2011, online dal 30 novembre 2015, consultato il 13 janvier 2021. URL: http://journals.openedition.org/studifrancesi/5949 ; DOI: https:// doi.org/10.4000/studifrancesi.5949

Questo documento è stato generato automaticamente il 13 janvier 2021.

\section{(c) $(1) \odot$}

Studi Francesi è distribuita con Licenza Creative Commons Attribuzione - Non commerciale - Non opere derivate 4.0 Internazionale. 


\title{
La Valeur de l'Art. Exposition, marché, critique et public au XVIII siècle, sous la direction de Jesper Rasmussen
}

\author{
Bianca Gai
}

\section{NOTIZIA}

La Valeur de l'Art. Exposition, marché, critique et public au XVIII ${ }^{\mathrm{e}}$ siècle, sous la direction de Jesper RASMUSSEN, Paris, Champion, 2009 («Les dix-huitièmes siècles», 126), pp. 261.

1 Nel volume si confrontano sul tema del valore dell'arte specialisti di diverse discipline, che spaziano dalla Letteratura, alla Filosofia, alla Storia dell'arte. Il progetto è organizzato secondo due direzioni di ricerca: la prima concerne la valorizzazione dell'arte nelle sue manifestazioni concrete (pratiche di circolazione, esposizione e vendita), la seconda riguarda i modi della sua traduzione in discorso nella teoria e nella critica. Apre la raccolta Annie BECQ (Esthétique, société, marché, pp. 19-47), che ricostruisce la mutazione dello statuto dell'artista nel corso del xviII secolo. Affrontando in parallelo il problema della nascita del concetto di bello ideale e il processo di commercializzazione dell'arte, ne dimostra la connessione: l'estetica moderna nasce quando si afferma una nozione dell'artista come genio creatore, che a sua volta è debitrice, come ha dimostrato Pierre Bourdieu, della collocazione sul mercato dell'opera d'arte. Da una prospettiva foucaultiana di critica dell'ordinamento cronologico-narrativo assunto dalla storia delle idee, si diparte l'analisi di Nicolas VIEILlesCAZEs (Qu'est-ce que parler des "beaux-arts"? Le cas de l'abbé Batteux, pp. 49-71), il quale intende svincolare la teoria di Batteux da una storia lineare dell'estetica. La prospettiva di Batteux non è estetica, ma poetica: la concezione del carattere innovativo della fusione delle arti, attribuitagli dagli storici delle idee, è assente nella sua opera, che se dà per scontata un'unità delle arti, la colloca però sotto l'egida della poesia. Oggetto d'analisi dell'intervento di Nathalie MANCEAU (Raillerie et fascination: le 
critique d'art face aux tableaux de l'exposition du Louvre, pp. 75-97) sono invece le Lettres à un amateur di Guillaume Baillet de Saint-Julien, brochure apparsa al Salon del 1750. La vicinanza di ispirazione dell'opuscolo con il registro letterario illustra la debolezza della critica d'arte come genere nascente nel xviII secolo.

Dello studio di trattati, stampe e illustrazioni dell'epoca si avvale Eva KERNBAUER (Jugements de valeur: la formation du public comme autorité d'évaluation esthétique, pp. 99-128), per tracciare la storia dei rapporti tra pubblico e giudizio estetico tra XVII e XVIII secolo. Il concetto di pubblico tende a variare con l'evoluzione delle teorie artistiche e degli avvenimenti istituzionali e politici. Per esempio, almeno a partire da Du Bos, il pubblico è definito come concetto astratto e la ricezione estetica diventa pratica sociale, al di là del riferimento all'erudizione del singolo. Il saggio di Patrick MICHEL (Lieux et dispositifs de la collection en France dans la seconde moitié du XVIII siècle, pp.131-159) illustra l'evoluzione delle modalità di presentazione delle collezioni d'arte, valutando i modi in cui i testi teorici hanno impattato sulla disposizione degli spazi. La "mise en scène" della collezione costituiva spesso un vero progetto museografico, testimoniando l'esistenza di una riflessione teorica che anticipa i grandi dibattiti sulla ristrutturazione dei musei di fine Settecento. Guillaume GLORIEUX ("M. Stiémart, peintre et bon copiste?": ébauche d'un portrait de François-Albert Stiémart, 1680-1740, pp.161-183) consacra il suo studio alla pratica, molto diffusa nel secolo, del copismo e in particolare alla figura del pittore M. Stiémart, al servizio del re a Versailles. La sua attività ci illumina sul gusto dell'élite aristocratica e sulle lotte d'influenza e le rivalità in seno al milieu artistico parigino della prima metà del secolo. Ángela JULIBERT-JIMÉNEZ (Les salons de l'Académie de Saint-Luc, 1751-1774, pp. 187-213) si sofferma sull'importanza dell'ancora poco studiata Académie de Saint-Luc (1667), tentativo di riprodurre la struttura della Académie Royale de Peinture et de Sculpture, in modo che anche gli esclusi dalla più influente accademia potessero accedere ai vantaggi e al prestigio connessi al ruolo d'artista.

Chiude la raccolta Céline SPECTOR (De Rousseau à Smith: esthétique et démocratique de la sensibilité et théorie économiste de l'esthétique, pp. 215-249), rintracciando le relazioni tra il discorso sull'arte e il discorso sull'economia negli esempi di Jean Jacques Rousseau e Adam Smith. Da un lato emerge, in Rousseau, un'«esthétique démocratique de la sensibilità»: nelle società civili corrotte, l'arte s'inserisce tra le ostentazioni del lusso che fomentano la diseguaglianza e l'ingiustizia, nonostante sia ancora possibile concepire forme di apprezzamento estetico che rinsaldino il legame sociale. Alla concezione di Rousseau si oppone la «théorie économiste de l'esthétique» di Adam Smith, secondo la quale l'assimilazione della valutazione estetica alle norme dominanti dell'economia non danneggia, anzi favorisce il benessere della società. 